\title{
Polysialylated Neural Cell Adhesion Molecule Is Necessary for Selective Targeting of Regenerating Motor Neurons
}

\author{
Colin K. Franz, ${ }^{1}$ Urs Rutishauser, ${ }^{2}$ and Victor F. Rafuse ${ }^{1}$ \\ ${ }^{1}$ Department of Anatomy and Neurobiology, Dalhousie University, Halifax, Nova Scotia, Canada B3H 1X5, and ${ }^{2}$ Sloan-Kettering Institute, Memorial Sloan- \\ Kettering Cancer Center, Program in Cell Biology, New York, New York 10021
}

It is well established that peripheral nerves regenerate after injury. Therefore, incomplete functional recovery usually results from misguided axons rather than a lack of regeneration per se. Despite this knowledge very little is known about the molecular mechanisms regulating axon guidance during regeneration. In the developing neuromuscular system the neural cell adhesion molecule (NCAM) and its polysialic acid (PSA) moiety are essential for proper motor axon guidance. In this study we used a well established model of nerve transection and repair to examine whether NCAM and/or PSA promotes selective regeneration of femoral motor nerves in wild-type and NCAM (-I-) mice. We found that regenerating axons innervating the muscle pathway and, to a lesser extent, cutaneous axons in the sensory pathway reexpress high levels of PSA during the time when the cut axons are crossing the lesion site. Second, we found that motor neurons in wild-type mice preferentially reinnervated muscle pathways, whereas motor neurons in $\operatorname{NCAM}(-/-)$ mice reinnervated muscle and cutaneous pathways with equal preference. Preferential regeneration was not observed in wild-type mice when PSA was removed enzymatically from the regenerating nerve, indicating that this form of selective motor axon targeting requires PSA. Finally, transgenic mice were used to show that the number of collateral sprouts, their field of arborization, and the withdrawal of misprojected axons were all attenuated significantly in mice lacking PSA. These results indicate that regenerating motor axons must express polysialylated NCAM, which reduces axon-axon adhesion and enables motor neurons to reinnervate their appropriate muscle targets selectively.

Key words: PSA-NCAM; motor neuron; regeneration; sprouting; axon guidance; PMR

\section{Introduction}

The degree of functional recovery attained after a peripheral nerve injury is, to a large extent, dependent on the number of lesioned axons that have reinnervated their appropriate postsynaptic target(s) (Fu and Gordon, 1997). During development it is well established that growing axons respond to a combination of both long- and short-range guidance cues that specifically direct them to their correct target(s) (Tessier-Lavigne and Goodman, 1996). Moreover, many of the guidance molecules and cellular mechanisms responsible for precise targeting of axons during development have been well characterized (Chisholm and Tessier-Lavigne, 1999). Therefore, it is rather surprising that very little is known about the molecular mechanisms regulating selective targeting of regenerating peripheral axons. One explanation for this apparent oversight is the general conception that regen-

Received Sept. 15, 2004; revised Jan. 5, 2005; accepted Jan. 7, 2005.

This work was supported by grants from the Medical Research Council of Canada (V.F.R.), the Canadian Institutes for Health Research (V.F.R.), and the Nova Scotia Health Research Foundation (NSHRF) (V.F.R.). C.K.F. is funded by an NSHRF graduate student scholarship award. We thank Dr. Tessa Gordon for helpful comments during the preparation of this manuscript and David Fillmore for technical assistance. We also thank Monique Guilderson (Martime Medical Design) for her artwork. The PSA antibody was obtained from the Developmental Studies Hybridoma Bank under the auspices of the National Institute of Child Health and Human Development and maintained by the University of lowa Department of Biology.

Correspondence should be addressed to Dr. Victor F. Rafuse, Department of Anatomy and Neurobiology, Dalhousie University, Sir Charles Tupper Medical Building, 5850 College Street, Halifax, Nova Scotia, Canada B3H 1X5. E-mail:vrafuse@dal.ca.

DOI:10.1523/JNEUROSCI.4880-04.2005

Copyright $\odot 2005$ Society for Neuroscience $\quad$ 0270-6474/05/252081-11\$15.00/0 erating axons do not reinnervate their original targets selectively after peripheral nerve injury (Sunderland, 1978). However, there are several examples in which selective axon regeneration likely occurs. For example, physiologically distinct classes of fast and slow motor neurons have a propensity to reinnervate their appropriate class of muscle fibers preferentially (Soileau et al., 1987; Brown and Everett, 1990, 1991; Nemeth et al., 1993; Unguez et al., 1993; Rafuse and Gordon, 1998; Wang et al., 2002). Similarly, transected motor neurons reinnervate the diaphragm in the same topographically correct manner as occurs during development (Laskowski and Sanes, 1988), suggesting that many of the same guidance cues expressed during embryogenesis are reexpressed after peripheral nerve injury.

Developmental biologists often have applied simple but extremely useful model systems to identify specific axon guidance molecules. To this end, Brushart and colleagues developed a femoral nerve regeneration model that reproducibly demonstrates that regenerating motor neurons selectively grow down distal motor pathways although they have equal access to sensory pathways (Brushart, 1988, 1993; Al-Majed et al., 2000). This example of selective motor neuron regeneration is known as preferential motor reinnervation (PMR).

The molecular mechanisms regulating PMR are not well understood. However, there are several lines of evidence to suggest that the neural cell adhesion molecule (NCAM) and its polysialic acid (PSA) moiety are involved. PSA and NCAM are both reexpressed by regenerating motor axons after peripheral nerve in- 
jury (Zhang et al., 1995; Rutishauser and Landmesser, 1996). During development motor axons must express PSA to innervate their appropriate muscle target(s) selectively (Tang et al., 1992, 1994). Finally, the speed and accuracy of PMR are increased with brief electrical stimulation (Al-Majed et al., 2000; Brushart et al., 2002), which suggests that the guidance molecules responsible for PMR can be regulated by neuronal activity. Neuronal expression of PSA is increased with cell activity (Kiss et al., 1994).

To determine whether PSA and NCAM regulate PMR, we compared motor axon regeneration in wild-type and NCAM null $(-/-)$ mice. We found that PMR was present 3 weeks after nerve transection in wild-type, but not NCAM $(-/-)$, mice. PMR was also absent in wild-type mice when PSA was removed enzymatically from the regenerating nerve. Finally, transgenic mice were generated to show that axonal sprouting was restricted, and withdrawal of misprojecting axons more inhibited, in mice lacking PSA compared with wild-type mice. Together, these results indicate that PSA-dependent growth of motor axons is required for selective targeting of regenerating motor axons.

Parts of this paper have been published in abstract form (Franz and Rafuse, 2003).

\section{Materials and Methods}

Mice. Five different strains of mice were used in this study. Wild-type C57BL/6 mice were obtained from Charles River (Wilmington, MA). In the majority of the experiments the same strain of NCAM $(-/-)$ mice on a C57/B6 background, generated by Cremer et al. (1994), was used. To control for possible strain differences, we obtained a second strain of NCAM $(-/-)$ mice from The Jackson Laboratory (Bar Harbor, MA). This latter strain has been backcrossed extensively with C57BL/6 mice for at least nine generations (Delling et al., 2002). A transgenic mouse line $(m H b 9-G f p 1 b)$, in which enhanced green fluorescent protein (eGFP) is expressed under the control of the mouse $\mathrm{Hb} 9$ promotor (Wichterle et al., 2002) (a kind gift from Dr. T. M. Jessell, Columbia University, New York, NY), was used specifically to visualize motor axons in wild-type mice. Specifically to visualize motor axons in NCAM $(-/-)$ mice, we bred $m H b 9-G f p 1 b$ mice with NCAM $(-/-)$ mice to generate NCAM $(-/-)$ mice that express the $m H b 9-G f p 1 b$ gene. We designated these latter mice NCAM (-/-)/Hb9-Gfp. All strains of mice were housed and bred locally in the animal facilities at Dalhousie University.

Mouse genotyping was performed by PCR. The NCAM mutant allele was detected as a 336 bp DNA fragment generated by PCR, using a $5^{\prime}$ primer that anneals to the NCAM sequence ( $5^{\prime}$-GCT CAT GTT CAA GAA TGC ACC) and a 3' primer in the neo sequence ( $5^{\prime}$-ATC CAT CTT GTT CAA TGG CCG). The NCAM wild-type allele was detected as a 403 bp DNA fragment, using the $5^{\prime}$ primer described above and a $3^{\prime}$ primer in the NCAM sequence ( $5^{\prime}$-CCT CAG GTA TTA TGG TGT TGG). Amplification included the following: $95^{\circ} \mathrm{C}$ for $1 \mathrm{~min} ; 55^{\circ} \mathrm{C}$ for $30 \mathrm{~s} ; 72^{\circ} \mathrm{C}$ for 1 min; 30 cycles of $94^{\circ} \mathrm{C}$ for $30 \mathrm{~s}, 58^{\circ} \mathrm{C}$ for $30 \mathrm{~s}, 72^{\circ} \mathrm{C}$ for $30 \mathrm{~s}$; and, finally, $72^{\circ} \mathrm{C}$ for $5 \mathrm{~min}$. The eGFP allele was detected as a $650 \mathrm{bp}$ DNA fragment generated by PCR, using a $5^{\prime}$ primer ( $5^{\prime}$-GCT GTT CAC CGG GGT GGT GC) and a 3' primer (5'-TCC AGC AGG ACC ATG TGA TC). Amplification included the following: $94^{\circ} \mathrm{C}$ for $5 \mathrm{~min} ; 30$ cycles of $94^{\circ} \mathrm{C}$ for $30 \mathrm{~s}$, $60^{\circ} \mathrm{C}$ for $60 \mathrm{~s}, 72^{\circ} \mathrm{C}$ for $60 \mathrm{~s}$; and, finally, $72^{\circ} \mathrm{C}$ for $5 \mathrm{~min}$.

Nerve transection and repair. All surgeries were performed on young adult (8-12 weeks) mice under aseptic operating conditions. Mice were anesthetized with isoflurane (Baxter, Toronto, Ontario, Canada), a small incision was made in the skin to expose the femoral nerve, and one of three nerve transection and repair surgeries was performed (Fig. 1). (1) For immunohistochemistry the muscle and cutaneous pathways of the femoral nerve of C57BL/6 mice were cut sharply at points $3 \mathrm{~mm}$ distal to their bifurcation from the common nerve trunk (Fig. 1A). The proximal stumps were joined surgically to the distal stumps with 11-0 nylon sutures (Fine Science Tools, North Vancouver, British Columbia, Canada). (2) For analysis of PMR the femoral nerve was transected and repaired 2 $\mathrm{mm}$ proximal to its bifurcation into separate muscle and cutaneous pathways. This transection site is distal to the point at which the iliacus nerve
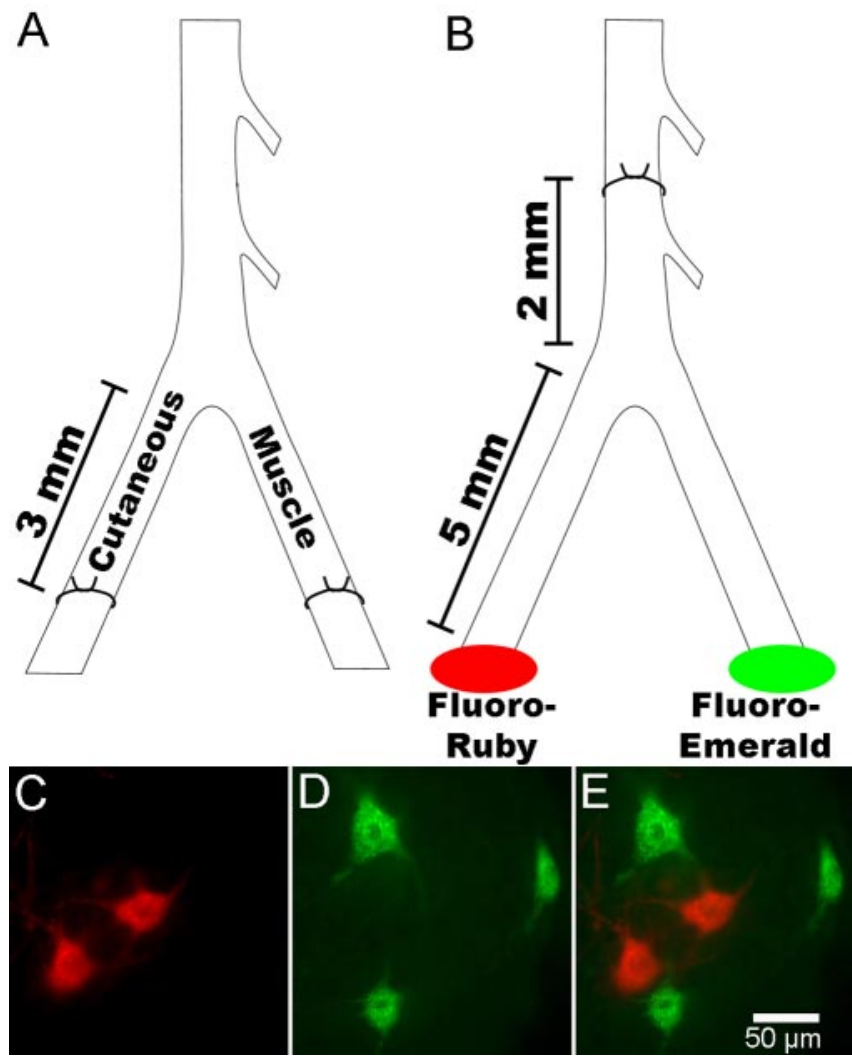

Figure 1. Diagrammatic representations of surgeries performed and examples of retrogradely labeled motor neurons. $\boldsymbol{A}$, The femoral nerve bifurcates into a cutaneous nerve branch that innervates the skin of the lower leg and a muscle nerve branch that supplies the quadriceps femoris muscle. The expression of PSA on regenerating axons in each nerve was determined by cutting the branches $3 \mathrm{~mm}$ distal to the bifurcation point and suturing together the proximal and distal stumps. $\boldsymbol{B}$, PMR was assessed by cutting and repairing the femoral nerve $2 \mathrm{~mm}$ proximal to the bifurcation point. Application of the neurotracers fluororuby and fluoroemerald was used to quantify motor neurons that regenerated their axons $5 \mathrm{~mm}$ into the muscle and cutaneous branches of the cut and repaired femoral nerve. The cell bodies of motor neurons retrogradely labeled with fluororuby $(\boldsymbol{C})$ can be distinguished readily from those labeled with fluoroemerald (D). $\boldsymbol{E}$, Overlay of $\boldsymbol{C}$ and $\boldsymbol{D}$

separates from the main femoral nerve, but it is proximal to the divergence of the pectineus nerve (Fig. $1 B$ ). The femoral nerve was cut sharply, and the proximal and distal nerve stumps were secured together with a single 11-0 nylon suture. Care was taken to ensure that the suture held the proximal and distal femoral nerve stumps tightly together so that their cut ends were closely apposed. Because of the very small diameter of the mouse femoral nerve $(\sim 300 \mu \mathrm{m})$, it was not possible to align the proximal and distal femoral nerve stumps convincingly with the same precision as described previously in the rat (Brushart, 1988, 1993; Al-Majed et al., 2000). Thus no attempt was made to do so. (3) To remove PSA selectively from the regenerating nerve in wild-type mice, we injected 0.5 $\mu \mathrm{l}(8.7 \mathrm{U} / \mu \mathrm{l})$ of endoneuraminidase- $\mathrm{N}($ Endo-N) or $0.9 \%$ saline into the femoral nerve $2 \mathrm{~mm}$ proximal to its bifurcation into separate muscle and cutaneous pathways $30 \mathrm{~min}$ before the nerve was cut and sutured as described above. As shown previously, Endo- $\mathrm{N}$ injected into the chick hindlimb effectively removes PSA from developing nerve and muscle fibers for several days in vivo (Landmesser et al., 1990; Rafuse and Landmesser, 2000). For pain relief all of the operated mice were administered ketoprofen $(5 \mathrm{mg} / \mathrm{kg})$ after the surgeries.

Immunohistochemistry. To study the expression of PSA in regenerating muscle and cutaneous axons, we harvested the muscle and cutaneous pathways of the femoral nerve from wild-type C57BL/6 mice at 3, 8, and $15 \mathrm{~d}$ after transection and repair (surgery 1 , described above). To study the reexpression of PSA on distal muscle targets in Endo-N- and salineinjected mice, we dissected out the quadriceps femoris muscle of wild- 
type C57BL/6 mice at $7 \mathrm{~d}$ after transection, injection, and repair (surgery 3 , described above). Mice were anesthetized deeply with $300 \mu \mathrm{l}$ of Somnotol $(240 \mathrm{mg} / \mathrm{ml})$ and perfused with $4 \%$ paraformaldehyde (PFA). Segments $(3 \mathrm{~mm})$ of the muscle and cutaneous branches of the femoral nerve were dissected free from the surrounding tissue, postfixed in $4 \%$ PFA overnight at $4^{\circ} \mathrm{C}$, and cryoprotected in $30 \%$ sucrose-PBS overnight at $4^{\circ} \mathrm{C}$. The harvested nerve segments contained axons located immediately proximal to the original site of transection (Fig. 1A). Muscles and nerves were frozen in O.C.T. (Miles, Elkhart, IN), and $14 \mu \mathrm{m}$ coronal sections were cut with a cryostat. Muscle and nerve sections were immunolabeled with 5A5 (a monoclonal IgM antibody that exclusively recognizes PSA; Developmental Studies Hybridoma Bank, Iowa City, IA) (Dodd et al., 1988). The muscle and nerve sections were incubated overnight at $4^{\circ} \mathrm{C}$ in the $5 \mathrm{~A} 5$ primary antibody, washed several times in PBS, incubated for $90 \mathrm{~min}$ at room temperature in a rhodamine-conjugated IgM secondary antibody (1:500; Sigma, Oakville, Ontario, Canada), washed several times in PBS, and then mounted in 50\% glycerin-PBS containing $0.03 \mathrm{mg} / \mathrm{ml}$-phenylenediamine. Sections for comparison were photographed at the same time, and with identical exposures, using a Nikon (Tokyo, Japan) CoolPix 4500 digital camera attached to an upright Leica DM/LFS fluorescent microscope (Nussloch, Germany).

The cross-sectional areas (CSAs) of muscle fibers in wild-type and NCAM (-/-) mice were measured from quadriceps femoris muscles harvested from nonperfused animals. The muscles were mounted quickly on cork with O.C.T. and frozen in isopentane that was cooled with dry ice. Sections $(14 \mu \mathrm{m})$ were cut with a cryostat and photographed with a Nikon CoolPix digital camera; CSAs were measured with Scion (Frederick, MD) Image software.

Retrograde labeling of motor neurons. At the end of the regeneration period (i.e., at 1.5, 3 , and 6 weeks) the muscle and cutaneous branches of the femoral nerve in mice that received surgery 2 or 3 (see above) were isolated, cut, and backlabeled with neurotracers to quantify the number of motor neurons innervating each branch. Under aseptic conditions the mice were anesthetized with isoflurane, and the femoral nerve was exposed. A 10\% solution of fluororuby (Molecular Probes, Eugene, OR) or fluoroemerald (Molecular Probes) was applied randomly to the muscle or cutaneous branch of the femoral nerve $5 \mathrm{~mm}$ distal to the point of bifurcation (Fig. $1 B$ ). In each mouse one branch was labeled with fluororuby while the other was labeled with fluoroemerald. Application of the neurotracers was performed by presoaking the dyes in a piece of Gelfoam (Upjohn, Don Mills, Ontario, Canada) that subsequently was placed at the end of a freshly cut nerve stump for $1 \mathrm{~h}$. To avoid crosscontamination of dyes, we created temporary wells around the sensory and motor nerve branches with petroleum jelly and cotton. Before the wound was closed, the Gelfoam and wells were removed, and sterile saline was used to wash out thoroughly any dye not taken up by the axons. The mice were permitted to recover for $3 \mathrm{~d}$ to allow sufficient time for the retrograde neurotracers to be transported back to the cell bodies. Then the mice were anesthetized deeply with Somnotol and perfused with $4 \%$ PFA. The lumbar region of the spinal cords was dissected free from the surrounding vertebrae, postfixed in $4 \%$ PFA overnight at $4^{\circ} \mathrm{C}$, and finally immersed in $30 \%$ sucrose-PBS overnight at $4^{\circ} \mathrm{C}$ for cryoprotection. Spinal cords then were frozen in O.C.T. and sectioned at $40 \mu \mathrm{m}$ with a cryostat.

Motor neuron counting. The total pool of labeled motor neurons was counted by a person who was unaware of which dye had been applied to the muscle and cutaneous pathways. Cells were counted only if their nucleus was present in the section, and raw cell counts were corrected via the method described by Abercrombie (1946).

Analysis of regenerating motor axons. Surgery 2 or 3 (see above) was performed on $m H b 9-G f p 1 b$ and NCAM (-/-)/Hb9-Gfp mice. At 3 weeks after nerve transection the mice were anesthetized deeply with Somnotol and perfused with $4 \%$ PFA. A large segment of the femoral nerve, extending $3 \mathrm{~mm}$ proximal to the repair site to $3 \mathrm{~mm}$ distal to the bifurcation point, was dissected out for analysis. The femoral nerve was postfixed in $4 \%$ PFA overnight at $4^{\circ} \mathrm{C}$, cryoprotected overnight in $30 \%$ sucrose-PBS at $4^{\circ} \mathrm{C}$ and then frozen in O.C.T. Coronal sections $(14 \mu \mathrm{m})$ were cut with a cryostat, mounted in 50\% glycerin-PBS containing 0.03 $\mathrm{mg} / \mathrm{ml} p$-phenylenediamine, and imaged via a laser-scanning confocal microscope (LSM 510; Zeiss, Thornwood, NY). Representative sections from a region of the femoral nerve that was distal to the lesion but proximal to the pectineus branch (Fig. $1 B$ ) were selected for quantitative analysis by using Stereo Investigator software (MicroBrightField, Williston, VT). To quantify the amount of collateral sprouting, we counted the total number of eGFP-positive axons in the representative sections. To characterize quantitatively the distribution of motor axons within the nerve, we applied a $50 \mu \mathrm{m}^{2}$ box randomly to 30 sites in a single nerve cross section. The number of eGFP-positive fibers within each of the 30 boxes was counted and used to calculate the coefficient of variation $(\mathrm{CV}$; $\mathrm{SD} /$ mean $\times 100 \%)$. The CV allows for the comparison of variability between populations with different means. A low CV indicates that the axons were distributed evenly across the cross section, whereas a high $\mathrm{CV}$ indicates more segregation.

Statistical analysis. Unpaired Student's $t$ tests were used to make comparisons between groups. Means values are given with the SEM.

\section{Results \\ PSA is upregulated differentially on nerves reinnervating muscle and cutaneous pathways}

Although it is well established that NCAM is upregulated on axons and muscle fibers after peripheral nerve injuries (Covault and Sanes, 1985; Covault et al., 1986; Rieger et al., 1988), the extent to which PSA is expressed by regenerating peripheral axons is still, surprisingly, poorly understood. Furthermore, no study to date has distinguished between regenerating muscle and cutaneous neurons; thus it is not known whether these two distinct neuronal phenotypes differentially express PSA after injury. To address these questions, we took advantage of the unique anatomical characteristics of the murine femoral nerve. Like the majority of peripheral nerves, the femoral nerve is composed of both motor and sensory axons. However, unlike most peripheral nerves, the femoral nerve ultimately segregates into distinct muscle and cutaneous pathways that are approximately the same size (Brushart and Seiler, 1987; Brushart, 1988) (see Figs. 1, 4). The cutaneous branch contains only sensory neurons that innervate the skin, whereas the muscle branch contains both motor neurons and muscle afferents that innervate the quadriceps femoris muscle. This distinct characteristic of the femoral nerve enabled us to determine, first, whether PSA is expressed differentially by regenerating muscle and cutaneous neurons and, second, to determine whether PSA regulates PMR.

To determine to what extent PSA is expressed by regenerating muscle and cutaneous neurons, we transected and repaired the muscle and cutaneous branches of the femoral nerve $3 \mathrm{~mm}$ distal to their bifurcation (Fig. 1A). The animals were killed 3-15 d after transection, and the two $3 \mathrm{~mm}$ nerve segments immediately proximal to the transection sites were harvested and processed for PSA immunohistochemistry. For comparison, the same regions of the muscle and cutaneous branches of the femoral nerve also were harvested from unoperated control adult mice. Figure $2 A$ shows that PSA is expressed in the cutaneous, but not the muscle, pathway of the unoperated femoral nerve in adult wildtype mice. These results are in agreement with previous studies showing that, although PSA is downregulated in motor neurons and muscle afferents after birth, it is expressed continually by cutaneous neurons that project to laminas I and II of the dorsal horn in adult rats (Boisseau et al., 1991; Bonfanti et al., 1992; Seki and Arai, 1993).

As expected, the expression of PSA in both the muscle and cutaneous pathways increased significantly from control levels $3 \mathrm{~d}$ after complete nerve transection and repair (Fig. 2 B). Although it is impossible to determine the source of the PSA via light microscopy, previous studies that used electron microscopy have shown that the vast majority of PSA reexpressed in regener- 
Muscle
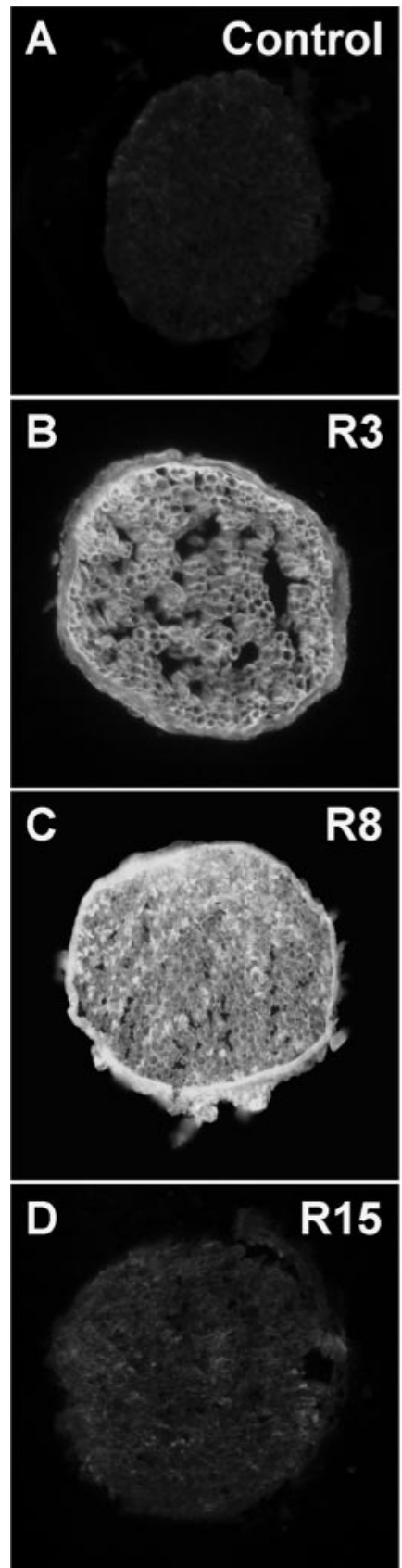

Cutaneous
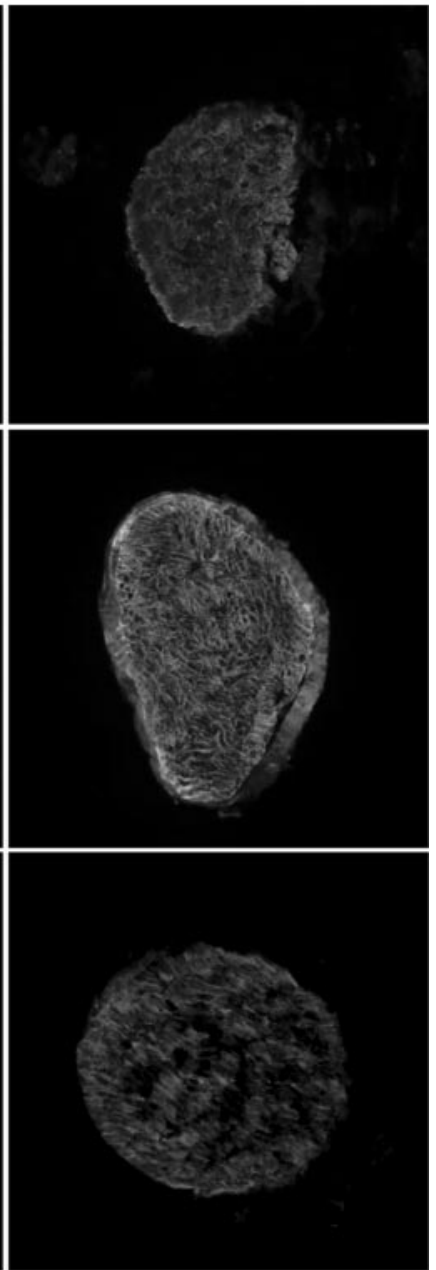

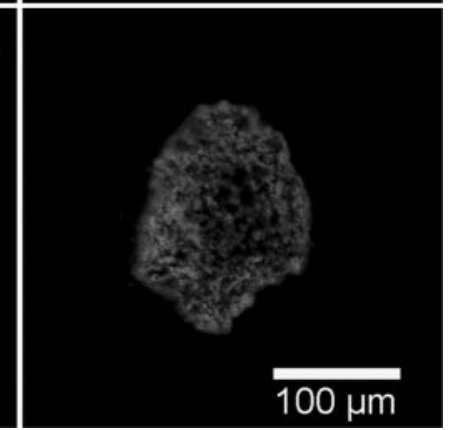

Figure 2. Regenerating muscle and cutaneous branches of the femoral nerve differentially express PSA. A, Immunolabeling shows that the cutaneous pathway normally expresses PSA, whereas the muscle pathway does not in unoperated adult wild-type mice. $\boldsymbol{B}$, PSA is upregulated by both the muscle and cutaneous pathways $3 \mathrm{~d}$ (R3) after nerve transection and repair. However, PSA levels are noticeably higher in the muscle pathway at R3. C, The muscle pathway, but not the cutaneous pathway, continues to express high levels of PSA $8 d$ (R8) after nerve transection and repair. $\boldsymbol{D}$, The intensity of PSA immunohistochemistry returns to control levels $15 \mathrm{~d}$ (R15) after surgery in both the motor and cutaneous pathways.

ating nerves is neural in origin (Zhang et al., 1995). Consequently, the dramatic upregulation of PSA in the muscle and cutaneous pathways most likely is attributable to the reexpression of PSA by regenerating axons and not to the synthesis of PSA by neighboring Schwann cells. Interestingly, the axons in the muscle pathway increased their expression of PSA to a much greater extent when compared with axons in the cutaneous pathway. The
PSA levels remained high on regenerating axons in the muscle pathway $8 \mathrm{~d}$ after nerve transection, whereas it returned to nearcontrol levels on axons in the cutaneous pathway (Fig. 2C). Intriguingly, the level of PSA near the transection site returned to preoperative levels $15 \mathrm{~d}$ after transection (Fig. 2D). Because withdrawal of polyneuronal innervation in reinnervated muscles takes 1-2 weeks (Thompson, 1978; Gorio et al., 1983) after nerve-muscle contact, these results indicate that the temporal expression of PSA along the axon corresponds better with the time it takes regenerating axons to cross a surgical repair site (Guttmann et al., 1942; Sunderland, 1978; Brushart et al., 2002) than the time it takes to restore mature synaptic endplates. Together, these results indicate that PSA is regulated differentially, up and down, by regenerating muscle and cutaneous neurons and that its downregulation along the axon occurs subsequent to crossing the surgical repair site but before the cessation of the reinnervation process.

PMR occurs in wild-type, but not NCAM $(-/-)$, mice

The temporal and spatial expression of PSA suggests that it could play a role in regulating selective axon targeting. To test this possibility directly, we adapted the well established rat model of PMR (Brushart, 1988, 1993; Al-Majed et al., 2000) to wild-type C57BL/6 mice and mice that lack both NCAM and PSA (i.e., NCAM -/-) (Cremer et al., 1994). A schematic of the mouse model that was used is shown in Figure $1 B$. The mouse femoral nerve was transected $2 \mathrm{~mm}$ proximal to the bifurcation point at which the nerve segregates into a muscle and cutaneous branch. The proximal end of the nerve was sutured directly to the distal stump with a single 11-0 monofilament suture. No attempts were made to reorient the proximal and distal stumps correctly during the suturing process. The animals were allowed to recover for 1.5, 3 , or 6 weeks. Motor neurons correctly innervating the muscle pathway, or incorrectly innervating the cutaneous pathway, were identified by backlabeling the axons with two fluorescent neurotracers $5 \mathrm{~mm}$ from the point of bifurcation (Fig. $1 B$ ) (for details, see Materials and Methods). To determine the number of femoral motor neurons in control C57BL/6 and NCAM $(-/-)$ mice, we performed preliminary experiments whereby the femoral muscle branch in unoperated mice was cut and backlabeled with a single fluorescent tracer. Using this technique, we determined that adult $\mathrm{C} 57 \mathrm{BL} / 6$ mice have $173 \pm 10.3(n=5)$ quadriceps femoris motor neurons, whereas adult NCAM $(-/-)$ mice have $163 \pm 4.7(n=4)$. The numbers of quadriceps femoris motor neurons in the C57BL/6 mice and NCAM $(-/-)$ mice were not significantly different from each other $(p<0.05)$, and both agree well with previously published data (McHanwell and Biscoe, 1981; Mears et al., 2003; Robinson and Madison, 2003). To rule out the possibility that NCAM $(-/-)$ mice have gross muscle abnormalities that could complicate the interpretation of our data, we measured the CSA of muscle fibers in quadriceps femoris muscles in wild-type and NCAM $(-/-)$ mice. The mean \pm SEM muscle fiber CSA in wild-type mice $\left(1962 \pm 81.2 \mu \mathrm{m}^{2}\right)$ was not significantly different from NCAM $(-/-)$ mice $\left(1845 \pm 83.5 \mu \mathrm{m}^{2}\right)$, indicating that muscle fiber development was not notably impaired in mice lacking NCAM (Moscoso et al., 1998; Rafuse et al., 2000).

As shown in Figure 3, <40 cut femoral motor neurons regenerated to a point $7 \mathrm{~mm}$ from the site of surgical repair in both wild-type C57BL/6 (Fig. 3B) and NCAM (-/-) (Fig. 3C) mice at 1.5 weeks after nerve transection. Those that did regenerate $7 \mathrm{~mm}$ showed the same propensity to grow down the inappropriate cutaneous pathway as down the appropriate muscle pathway (i.e., no PMR evident) (Fig. 3A-C). A few motor neurons $(<10)$ 


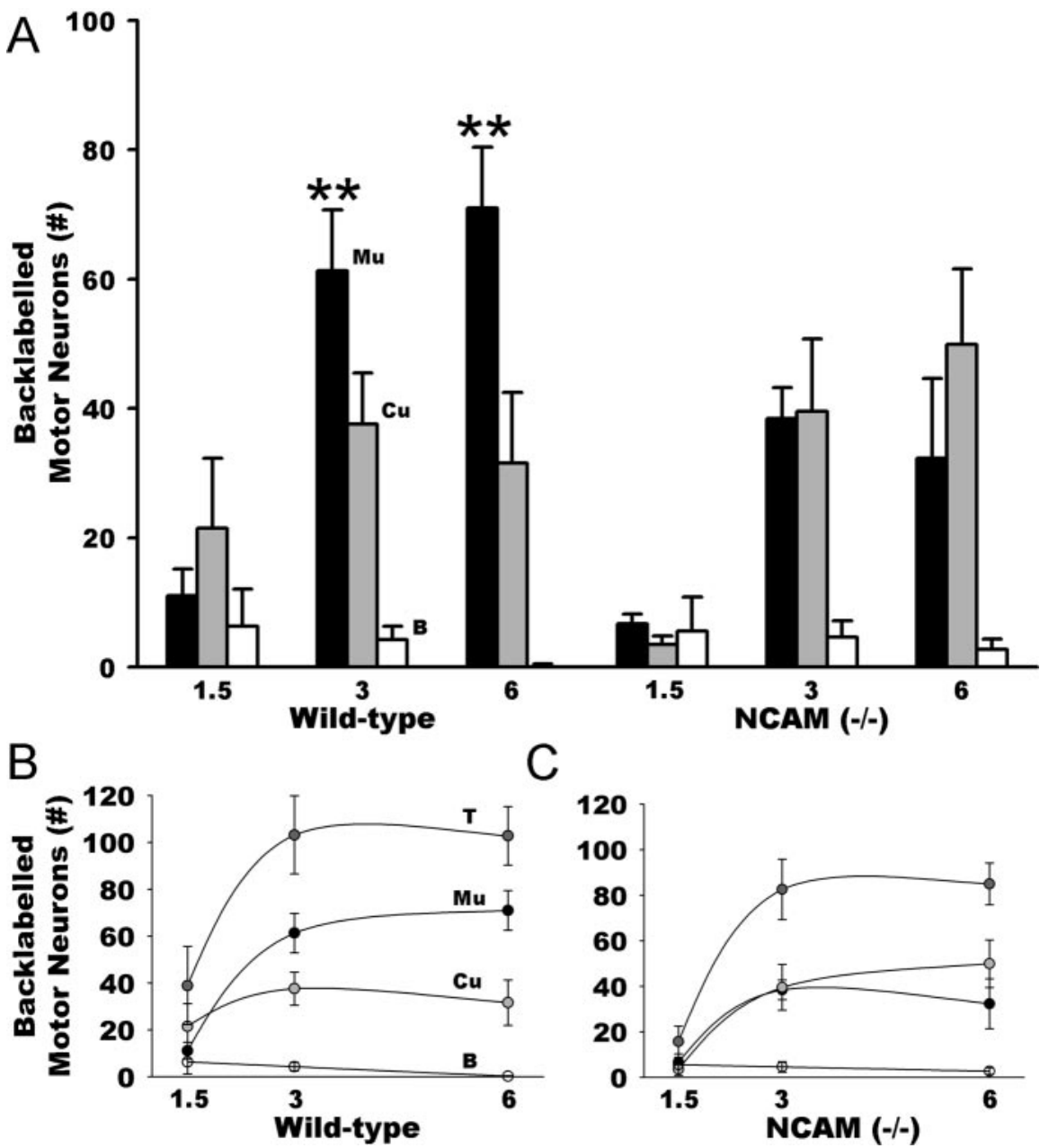

Figure 3. PMR occurs in wild-type, but not NCAM $(-/-)$, mice. $\boldsymbol{A}$, The mean \pm SEM number of retrogradely labeled motor neurons that regenerated into the appropriate muscle branch (black bars), inappropriate cutaneous branch (gray bars), and both branches (open bars) at 1.5, 3, and 6 weeks after femoral nerve transection and repair in wild-type and NCAM (-/-) mice $\left({ }^{* *} p<0.01\right.$, Mu compared with corresponding $(\mathbf{C})$. $\boldsymbol{B}, \boldsymbol{C}$, The same data as shown in $\boldsymbol{A}$, except that the total number (T) of regenerating neurons is included for both wild-type $(\boldsymbol{B})$ and NCAM $(-/-)(\boldsymbol{C})$ mice. Mu, Labeled axons in muscle branch; $\mathrm{Cu}$, labeled axons in cutaneous branch; $B$, labeled axons innervating both branches.

were double-labeled with both neurotracers, indicating that they had extended collateral axons $7 \mathrm{~mm}$ down both the muscle and cutaneous pathways (Fig. $3 A-C$ ). The number of motor neurons that regenerated $7 \mathrm{~mm}$ from the transection and repair site increased dramatically from 1.5 to 3 weeks after transection in both the wild-type (Fig. 3B) and NCAM (-/-) mice (Fig. 3C). As described previously in rats (Al-Majed et al., 2000; Brushart et al., 2002), this progressive increase in the number of backlabeled motor neurons over time indicates that mouse motor axons regenerate at different speeds. However, whereas staggered reinnervation in the wild-type mice was associated with progressively more motor neurons growing down the correct muscle pathway (Fig. $3 A, B)$, there was no evidence of PMR in NCAM $(-/-)$ mice (Fig. $3 A, C$ ). PMR also was not observed at 3 weeks in a different strain of NCAM $(-/-)$ mice that was backcrossed extensively with C57/B6 mice $(n=3)$ (data not shown). Thus PMR occurs in wild-type mice between 1.5 and 3 weeks after transection, and its emergence appears to require NCAM and/or PSA because it is completely absent in NCAM $(-/-)$ mice even after 6 weeks. Interestingly, there was only a small decline in the number of double-labeled motor neurons in wild-type mice between 1.5 and 6 weeks. Consequently, like the emergence of PMR in the rat, PMR in the mouse primarily occurs either because motor axons grow specifically into the appropriate muscle branch from the onset of regeneration or because incorrect collaterals are withdrawn proximal to the distal site of retrograde tracer application.

Previous PMR studies in mice indicate that there is a tremendous amount of variability in the number of motor axons that regenerate beyond the lesion site. For example, Robinson and Madison (2003) showed that between 22 and $161 \%$ of the total number of the transected motor neurons regenerated to the dye application site in the distal nerve stump. Despite this variable degree of innervation there was no correlation between the number of motor neurons that regenerated and the extent of PMR [calculated by dividing the number of motor neurons in the muscle branch by those in the sensory branch (Robinson and Madison, 2003)]. In the present study the number of motor neurons that regenerated beyond the lesion site varied between 33 and $85 \%$ in wild-type mice. As observed previously (Robinson and Madison, 2003), we found no correlation between the number of motor neurons that regenerated beyond the lesion site and the extent of PMR $\left(r^{2}=0.22\right)$. The reason for the wide range in regenerated motor neurons is not known. However, it is likely attributable to variability in the number of axons that regenerated through the site of surgical repair and not attributable to the fact that neurons died, because the number of motor axons proximal to the transection site was very similar to that observed in control femoral nerves (data not shown).

The absence of PMR in NCAM $(-/-)$ mice is not attributable to an abnormal distribution of femoral motor axons in mice lacking NCAM Normally, motor axons preferentially cluster in major limb nerves before they exit as a coherent group at the level of their appropriate muscle in birds (Lance-Jones and Landmesser, 1981; Milner et al., 1998), amphibians (Wilson et al., 1988; Brown et al., 1989), and mammals (Browne, 1950; Brown and Booth, 1983). Whether the same degree of motor axon compartmentalization occurs in NCAM $(-/-)$ mice is not known. It is possible that motor axons are not compartmentalized in NCAM $(-/-)$ mice and that this initial lack of motor axon organization hinders the process of PMR. To examine the topographical organization of femoral motor axons in wild-type mice, we used a transgenic mouse line $(m H b 9-G f p 1 b)$ in which eGFP is expressed under the control of the mouse $\mathrm{Hb} 9$ promotor (Wichterle et al., 2002). Hb9 is a homeodomain protein that is expressed by somatic motor neurons (Arber et al., 1999; Thaler et al., 1999); thus eGFP expression can be used to identify motor axons in nerve coronal sections. To visualize motor axons in $\operatorname{NCAM}(-/-)$ mice, we bred $m H b 9-G f p 1 b$ mice with NCAM $(-/-)$ mice to create eGFPexpressing motor neurons in NCAM $(-/-)$ mice (for details, see Materials and Methods). We designated these latter mice NCAM $(-/-) / H b 9-G f p$. As shown in the coronal sections in Figure 4, 
eGFP-expressing motor neurons are located, as expected, in the muscle (Fig. $4 A$, arrow), but not the cutaneous, pathway (Fig. $4 A$, arrowhead) of the femoral motor nerve in both wild-type and NCAM $(-/-)$ mice. The motor axons in the motor pathway innervate the quadriceps femoris muscle group. Coronal sections taken proximal to the bifurcation, but distal to the divergence of the iliacus nerve, indicate that the quadriceps femoris motor axons are clustered within the femoral nerve as a segregated, coherent group (Fig. $4 B$, encircled by yellow dotted lines) in both wildtype and NCAM $(-/-)$ mice. The eGFPexpressing axons in the small branch located outside the dotted lines presumably belong to motor neurons innervating the pectineus muscle. Quadriceps femoris motor axons remain clustered in the nerve proximal to the divergence of the iliacus, because the majority of the fluorescent axons is still located in the ventrolateral quadrant in both wild-type and NCAM $(-/-)$ mice (Fig. 4C). The distinct clustering of quadriceps femoris motor axons only becomes inconspicuous immediately distal to the point at which the spinal nerves join to form the femoral nerve (Fig. $4 D)$. Together, these results indicate that quadriceps femoris motor axons preferentially cluster in the femoral nerve long before they bifurcate to form a distinct motor pathway. Furthermore, quadriceps femoris motor axons in wild-type and NCAM $(-/-)$ mice are compartmentalized similarly and located topographically, indicating that an initial lack of motor axon organization does not account for the absence of PMR in NCAM-deficient mice.

\section{PMR is abolished after removal of PSA}

from regenerating wild-type femoral nerves

NCAM $(-/-)$ mice lack both NCAM and PSA (Cremer et al., 1994). Thus the absence of PMR in NCAM $(-/-)$ mice could be attributable to the loss of NCAM, PSA, or both. To distinguish among these possibilities, we enzymatically removed PSA from regenerating nerve in wild-type mice by injecting $0.5 \mu \mathrm{l}$ of Endo- $\mathrm{N}(8.7 \mathrm{U} / \mu \mathrm{l})$ into the lesion site of the femoral nerve $30 \mathrm{~min}$ before transection and surgical repair. To ascertain that PSA was removed completely from the regenerating femoral nerve during the onset of the regeneration process, we first performed preliminary experiments whereby Endo-N-injected femoral nerves were removed at $2 \mathrm{~d}$ (data not shown) and $7 \mathrm{~d}$ (Fig. 5B) after transection and were processed for PSA immunohistochemistry. Furthermore, to rule out the possibility that some Endo-N defused from the injection site and caused a systemic loss of PSA, we dissected out the distal muscle target (i.e., the quadriceps femoris muscle) of the femoral nerve $7 \mathrm{~d}$ after the nerve was transected and injected with Endo-N or is up and medial is left.
Muscle
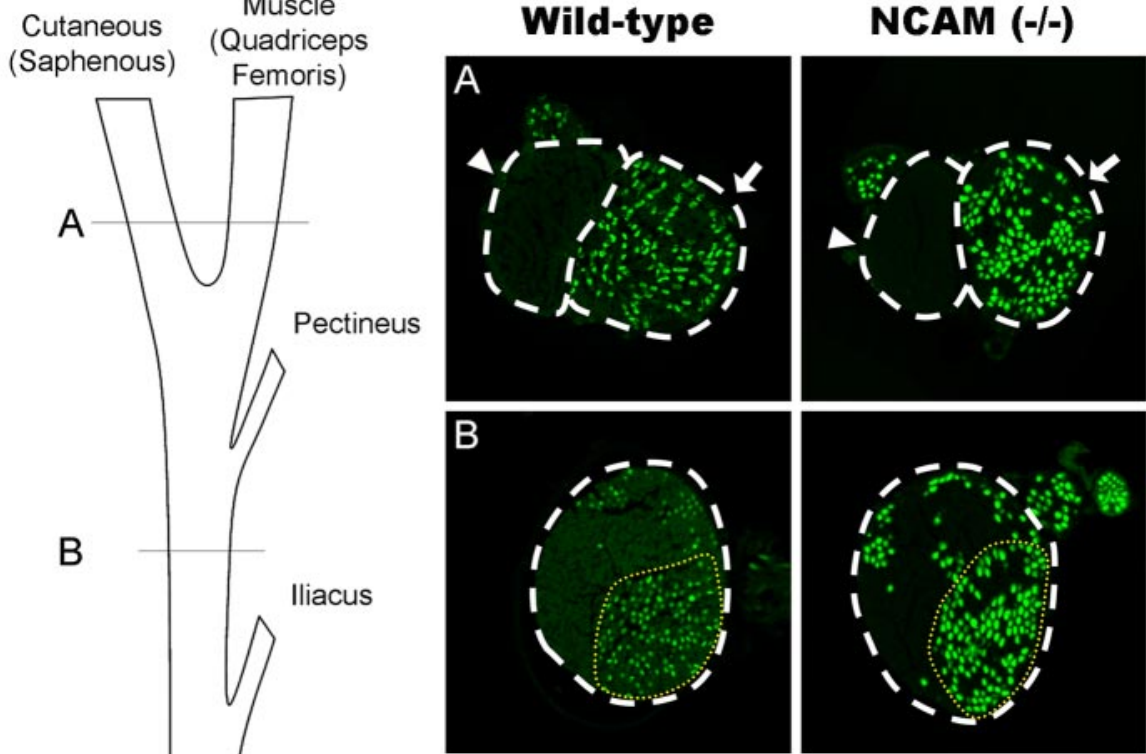

C

D
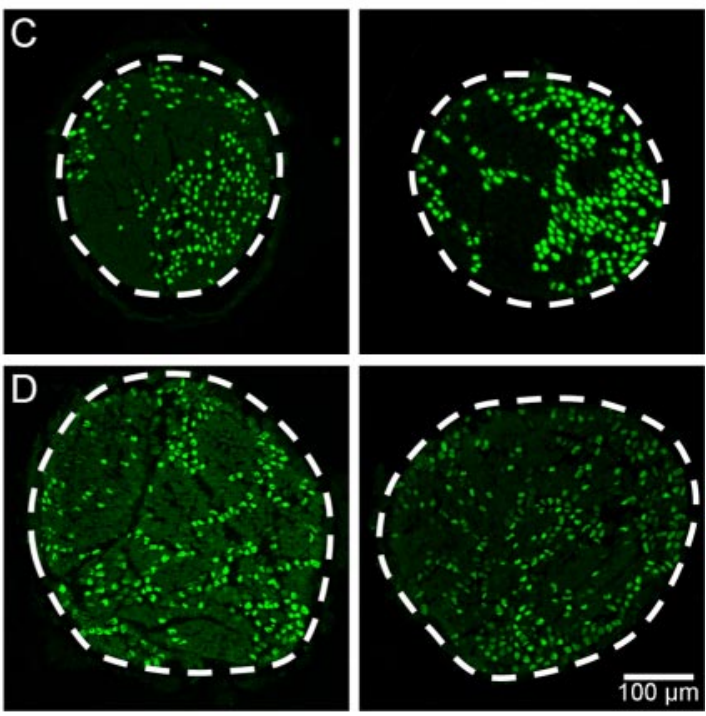

Figure 4. The distribution of quadriceps femoris motor axons in the femoral nerve is similar in wild-type and NCAM $(-/-)$ mice. Left, Diagram illustrating the basic anatomy of the murine femoral nerve. The site of the coronal sections, indicated by the horizontal lines, is illustrated to the right. $\boldsymbol{A}$, Coronal sections through the muscle (arrow) and cutaneous branches (arrowhead) of the femoral nerve in wild-type $m H b 9$-Gfp 16 and NCAM (-/-)/Hb9-Gfp mice indicate that eGFP-expressing axons are located only in the muscle branch. $\boldsymbol{B}$, Coronal sections taken proximal to the divergence of the pectineus nerve show that the quadriceps femoris motor axons are clustered (circled by yellow dotted line) in both wild-type $m H b 9-G f p 1 b$ and NCAM (-/-)/Hb9-Gfp mice. C, Quadriceps femoris motor axons are segregated predominantly in the ventrolateral (bottom right) quadrant of the femoral nerve in coronal sections taken between the divergence of the iliacus and obturator nerves in both wild-type $m H b 9$-Gfp $1 b$ and NCAM (-/-)/mHb9-Gfp mice. $\boldsymbol{D}$, The discrete grouping of quadriceps femoris motor axons is less distinct in coronal sections taken between the obturator nerve and the point at which the spinal nerves join to form the femoral nerve. In all sections, dorsal

saline. As shown in Figure 5, the level of PSA was substantially less on a regenerating Endo-N-injected femoral nerve (Fig. $5 B$ ) compared with a noninjected regenerating femoral nerve (Fig. 5A) $7 \mathrm{~d}$ after nerve transection and repair. In contrast, PSA was upregulated in denervated muscle fibers in both saline-injected (Fig. 5C) (Olsen et al., 1995) and Endo-N-injected (Fig. 5D) mice. In addition, the spatial distribution of PSA expression was very similar to that reported previously for NCAM in denervated rat muscles (Covault and Sanes, 1985). Thus PSA can be removed selectively from the regenerating femoral nerve, at least during the first week after surgery.

As shown in Figure 5E, like noninjected wild-type mice (Fig. 

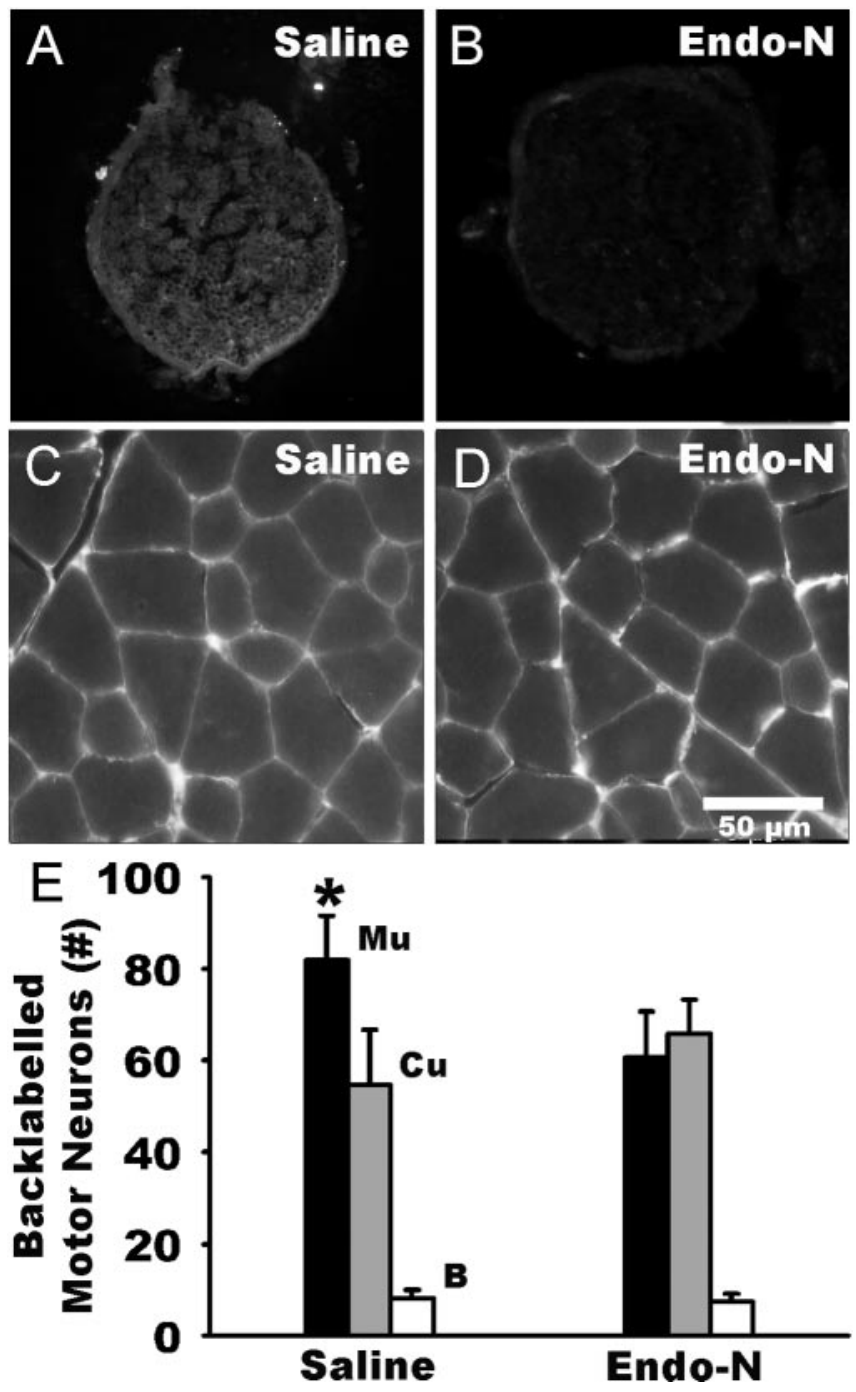

Figure 5. PMR does not occur in wild-type mice when PSA is removed enzymatically during the onset of regeneration. $\boldsymbol{A}$, PSA is expressed by regenerating axons in the femoral nerve of saline-injected wild-type mice $7 \mathrm{~d}$ after transection. $\boldsymbol{B}$, In contrast, no PSA is expressed by regenerating axons injected with Endo- $\mathrm{N}$ at the time of the surgery $7 \mathrm{~d}$ previously. $C, D, P S A$ expression in quadriceps muscle is similar $7 \mathrm{~d}$ after transection and repair of saline $(\boldsymbol{C})$ and Endo-N-injected $(\boldsymbol{D})$ femoral nerves. $\boldsymbol{E}$, The mean \pm SEM number of retrogradely labeled motor neurons that reinnervated the appropriate muscle branch (Mu; black bars), inappropriate cutaneous branch ( $\mathrm{Cu}$; gray bars), and both branches ( $\mathrm{B}$; open bars) 3 weeks after femoral nerve transection and repair in wild-type mice injected with saline or Endo-N. ${ }^{*} p<0.05$, Mu compared with corresponding $\mathrm{Cu}$.

$3 A$ ), saline-injected wild-type mice displayed PMR 3 weeks after transection and repair $(p<0.05)$. However, like the NCAM $(-/-)$ mice (Fig. $3 A)$, regenerating motor neurons in the Endo$\mathrm{N}$-injected mice did not show any preference to reinnervate the distal muscle pathway selectively. Consequently, the absence of PMR in the NCAM $(-/-)$ mice is most likely attributable to the loss of PSA from the regenerating nerve and not to the absence of NCAM. Furthermore, these results also support the conclusion that PMR does not occur in NCAM $(-/-)$ mice because they lack PSA and not because there are possible underlying strain differences.

Impaired sprouting of motor axon collaterals in NCAM (-/-) and Endo-N-treated mice Lesioned peripheral axons generally extend several collateral sprouts that explore, and then grow along, Schwann cell basal lamina tubes in the distal nerve stump (Ramon y Cajal, 1928). This generation of supernumerary collateral sprouts likely enhances regeneration accuracy, because it increases the chances that at least one collateral will enter the appropriate distal basal lamina tube that ultimately will direct it to its correct target (Brushart, 1988; Madison et al., 1999). Enzymatic removal of PSA from developing motor neurons reduces axonal branching (sprouting) by inappropriately enhancing axon-axon adhesion (Landmesser et al., 1990; Tang et al., 1992, 1994; Rafuse and Landmesser, 2000). Based on these developmental studies, it seemed reasonable to determine whether collateral sprouting is attenuated in mice lacking PSA. Consequently, the femoral nerves in wild-type $m H b 9-G f p 1 b, N C A M(-/-) / m H b 9-G f p$, and Endo-N-injected $m H b 9-G f p 1 b$ mice were transected and repaired as shown in Figure $1 B$. Three weeks later the segments between the transection site and bifurcation point were harvested and cut coronally. As expected from research by Ramon y Caja (1928), the number of motor fibers in the femoral nerve of wildtype mice increased dramatically after nerve transection and repair (Fig. $6 D$; compare $4 B, 6 A$ ), indicating that extensive collateral sprouting had occurred. The numbers of motor fibers in the femoral nerves of NCAM $(-/-)$ (compare Figs. $4 B, 6 B$ ) and Endo-N-injected mice (compare Figs. $4 B, 6 C$ ) were also higher than normal after nerve transection (Fig. 6D). However, in comparison with transected wild-type mice there were significantly fewer axons in mice lacking PSA $(p<0.05)$.

The distributions of collateral sprouts in the transected nerves immediately proximal to the pectineus branch were also visibly different in wild-type $m H b 9-G f p 1 b, N C A M(-/-) / m H b 9-G f p$, and Endo-N-injected $m H b 9-G f p 1 b$ mice (Fig. 6, compare $A-C$ ). In wild-type mice the motor fiber collaterals were distributed evenly across the entire cross section (Fig. 6A), whereas collateral sprouts in transected nerves lacking PSA appeared more segregated such that there were obvious areas without eGFP fibers (Fig. 6B,C). To characterize quantitatively the distribution of motor axons in an unbiased manner, we randomly applied a 50 $\mu \mathrm{m}^{2}$ box to 30 sites in a single nerve cross section. The number of eGFP-positive fibers within each box was counted. These numbers then were used to calculate a CV $(\mathrm{SD} /$ mean $\times 100 \%)$, which allowed for comparison of variability between populations with different means. The CVs then were used to assess quantitatively the clustering of motor fibers. As shown in Figure 6E, the CVs were high $(\sim 120 \%)$ in both wild-type and NCAM $(-/-)$ mice. These high CV values reflect the highly clustered distribution of motor axons in the uncut femoral nerves (Fig. $4 B$ ). The mean CV in wild-type mice 3 weeks after transection and repair was substantially lower $(\sim 60 \%)$ than in uncut wild-type and NCAM $(-/-)$ mice. This low CV reflects the even distribution of collateral sprouts in wild-type animals (Fig. 6A). The CVs were significantly greater $(p<0.01)$ in transected nerves from NCAM $(-/-)$ mice and Endo-N-injected mice ( $~ 90 \%)$ compared with transected nerves in wild-type mice (Fig. $6 E$ ). However, these CVs were also significantly less $(p<0.01)$ than uncut nerves in wild-type and NCAM $(-/-)$ mice (Fig. $6 E)$.Together, these results indicate that collaterals of regenerating motor axons do not become evenly distributed throughout the entire nerve in the absence of PSA, although they do become significantly less segregated than uncut axons.

Abnormal persistence of motor axon collaterals distal to the bifurcation occurs in mice lacking PSA

For individual motor axons to respond to distant guidance cues and branch from the main nerve trunk during development, they 
must decrease axon-axon adhesion by expressing PSA (Landmesser et al., 1990; Tang et al., 1992, 1994; Rutishauser and Landmesser, 1996). Studies in juvenile rats (Brushart, 1988, 1993) and nonhuman primates (Madison et al., 1999) suggest that PMR occurs, in part, because misguided regenerating femoral motor axons are "pruned" from inappropriate cutaneous pathways. Whether PSA is required for creating a level of de-adhesion necessary for axonal pruning is not known. Interestingly, our neurotracer studies showed only a small decline in the number of doublelabeled motor neurons over time, suggesting that selective pruning does not occur in wild-type mice (Fig. 3). However, it is possible that misguided mouse collaterals were withdrawn selectively before the distal site at which the fluorescent tracers were injected (Fig. $1 B$ ). To examine this possibility, we sectioned the muscle and cutaneous branches $3 \mathrm{~mm}$ distal to the bifurcation (i.e., $5 \mathrm{~mm}$ from the lesion site) in wild-type $m H b 9-G f p 1 b, N C A M(-/-) /$ $m \mathrm{Hb}$ 9-Gfp, and Endo-N-injected $m \mathrm{Hb}$ 9$G f p 1 b$ mice and counted the number of eGFP nerve fibers in single cross sections. Quite surprisingly, the number of eGFP fibers in the muscle branch was not visibly greater than that in the cutaneous branch 3 weeks after transection in both wild-type (Fig. 7A) and NCAM (-/-) mice (Fig. $7 B)$. However, when the number of eGFP fibers in the distal branches was expressed as a percentage of those counted in the nerve immediately distal to the transection site, it became clear that the distal branches contained fewer $(\sim 60 \%)$ motor axons in wild-type mice (Fig. 7C). In contrast, the distal branches had approximately the same number $(\sim 100 \%)$ of eGFP fibers as the nerve immediately distal to the lesion site in NCAM $(-/-)$ and Endo-Ninjected mice (Fig. 7C). Combined with our backlabeling experiments (Fig. 3), these results suggest that PMR occurs in wild-type mice because misguided motor axons do not regenerate very far down and/or they are withdrawn selectively from inappropriate distal pathways. PMR does not occur in mice lacking PSA, because misguided motor axons are not "pruned" and/or they continue to reinnervate inappropriate sensory pathways.

\section{Discussion}

Motor axons must express PSA to innervate their correct muscle targets selectively during chick neuromuscular development (Landmesser et al., 1990; Tang et al., 1992, 1994; Rafuse and Landmesser, 2000). Although PSA is not essential for regeneration per se (Moscoso et al., 1998), our results indicate that PSA is required for selective targeting of motor neurons during peripheral nerve regeneration in the adult mouse. Furthermore, using transgenic mice to visualize motor axons, we serendipitously showed that motor axons destined to innervate specific muscle groups are highly clustered in the main nerve trunk well before they diverge to form individual muscle nerves. These results have important clinical implications in the development of surgical strategies designed to improve functional recovery after peripheral nerve injury.

\section{PMR: rat versus mouse}

Since it was originally described in juvenile (Brushart, 1988, 1993 ) and adult (Al-Majed et al., 2000) rats, studies have shown that cut femoral motor neurons preferentially reinnervate muscle targets in nonhuman primates (Madison et al., 1999; Krarup et al., 2002), indicating that selective regeneration of femoral motor axons is not a phenomenon restricted to lower vertebrates. However, a recent study by Mears et al. (2003) indicated that PMR does not occur in C57BL/6 mice unless transection of the femoral nerve is followed by daily injections of antibodies to either myelin-associated glycoprotein or HNK-1. These results clearly disagree with the present study in which unambiguous PMR was reported in the same strain of C57BL/6 wild-type mice (Fig. 3). The reasons for this discrepancy are not obvious. However, there are differences between the two studies. Mears et al. (2003) transected the femoral nerve between the divergence of the iliacus and obturator nerves (T. M. Brushart, personal communication), whereas we cut the nerve more distally between the divergence of the iliacus and pectineus nerves (for anatomy, see Fig. 4). Although gross anatomical differences cannot account for the discrepancy because the organization of motor axons at the two levels is very similar (Fig. 4), it has been reported that PMR in the rat is better when the transection and repair occur at a site closer to the bifurcation (Madison et al., 1996). Consequently, it is possible that subtle molecular differences exist at these two sites that account for the conflicting mice results. 

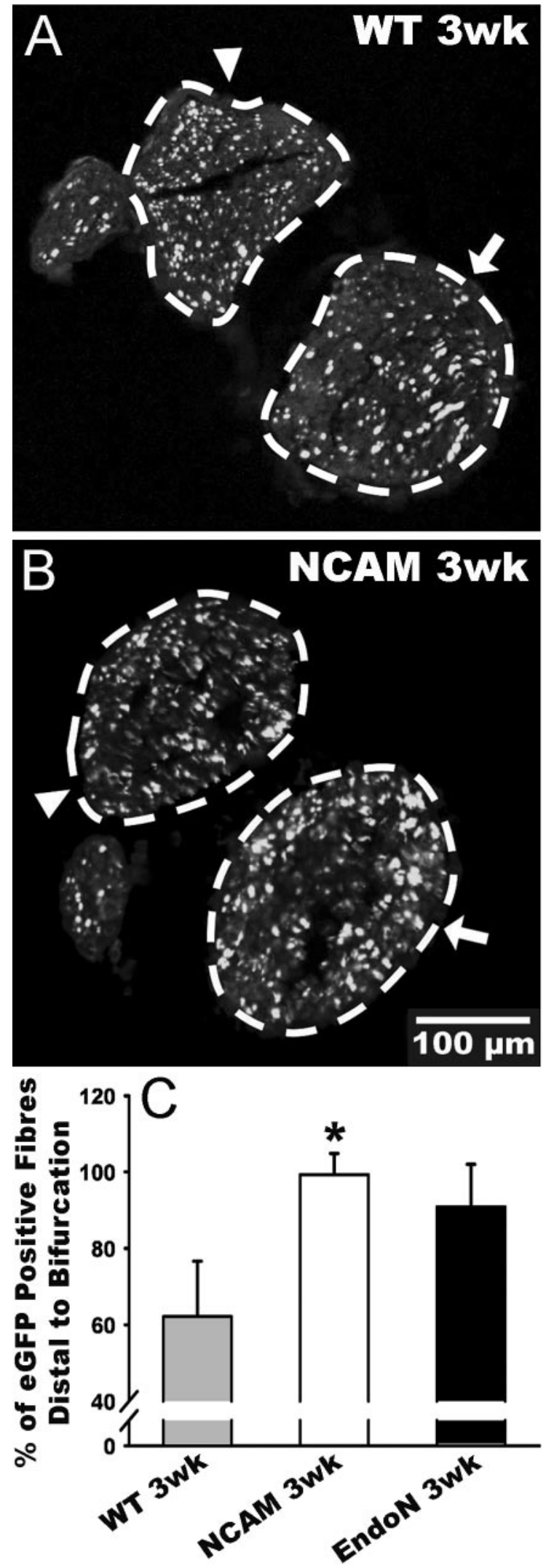

Figure 7. Abnormal persistence of motor axon collaterals distal to the bifurcation in NCAM $(-/-)$ and Endo-N-treated mice. $A, B$, Coronal section through wild-type $m H b 9-G f p 1 b(\boldsymbol{A})$ and $N C A M(-/-) / H b 9-G f p(B)$ femoral nerves $\sim 3 \mathrm{~mm}$ distal to their bifurcation. The number of motor axon collaterals found in the muscle pathway (arrow) is not visibly greater than in the cutaneous pathway (arrowhead) in either $\boldsymbol{A}$ or $\boldsymbol{B}$. C, Mean \pm SEM percentage of motor axon collaterals found distal to the bifurcation compared with the number of collaterals found

\section{PMR and PSA}

It is well established that, during the initial stages of peripheral nerve regeneration, each cut axon produces "dozens" of collaterals at the injury site (Ranson, 1912; Ramon y Cajal, 1928). Studies in rodents indicate that cut femoral axons typically extend 5-10 collateral sprouts, with fields of arborization spreading 50-100 $\mu \mathrm{m} 10 \mathrm{~d}$ after nerve transection and repair (Brushart et al., 1998; Brushart and Witzel, 2003). Although most sprouts presumably degenerate within a few days, two to four collaterals can persist in the distal nerve stump for 1-2 years (Shawe, 1955; Mackinnon et al., 1991; Nishimura et al., 1991).

The generation of supernumerary collateral sprouts is believed to enhance regeneration accuracy, because it increases the chances that at least one sprout will reinnervate an appropriate basal lamina tube (Brushart, 1988, 1993; Madison et al., 1999) that will direct it back to its original muscle target (Sanes et al., 1978; Nguyen et al., 2002). Although it is not known whether PSA regulates sprouting of single motor axons, several lines of evidence suggest that it does. The numbers of collateral sprouts diverging from motor nerves are higher when PSA expression is increased experimentally during neuromuscular development (Landmesser et al., 1990). Branching of individual retinal ganglion cells is reduced during development when PSA is removed enzymatically (El Maarouf and Rutishauser, 2003). Finally, we found that the distal stump near the lesion site contained three times more collateral sprouts than the proximal stump 3 weeks after transection and repair in wild-type mice. Mice lacking PSA had only two times as many axons (Fig. 6D). These results suggest that PSA promotes better PMR, because it enhances the formation of supernumerary collateral sprouts.

The probability of contacting an appropriate basal lamina tube is presumably greater when the field of arborization is large, because different sprouts from a single axon can sample many tubes distributed in various regions across the nerve cross section. Using detailed morphometric analysis, El Maarouf and Rutishauser (2003) recently showed that the volume of arborization of individual developing retinal ganglion cells is reduced when PSA is removed enzymatically. Our CV data (Fig. 6E) suggest that collateral sprouts from cut motor axons extend farther and form larger fields of arborization if they express PSA. Thus PSA also may promote PMR by enhancing the volume of arborization that, in turn, enables individual axons to sample many basal lamina tubes located at different sites throughout the nerve cross section.

Indiscriminately sampling, and then reinnervating, multiple basal lamina tubes cannot in itself promote PMR unless misprojected collateral sprouts are withdrawn selectively from inappropriate pathways (Brushart, 1988, 1993). Indeed we found that there were significantly fewer eGFP motor fibers in the distal pathways compared with immediately after the lesion site in wild-type mice 3 weeks after transection (Fig. 7C). This indicates either that collateral sprouts were being withdrawn or that they did not have sufficient time to reinnervate the distal branches in the first place. The latter seems unlikely because axons typically regenerate at a rate of $3 \mathrm{~mm} / \mathrm{d}$ (Guttmann et al., 1942; Seddon et al., 1943; Brushart et al., 2002), and the number of backlabeled motor neurons in transected wild-type mice did not change between 3 and 6 weeks after transection (Fig. 3). The visibly high

immediately distal to surgical repair in wild-type mHb9-Gfp1b (WT 3wk; gray bar), NCAM $(-/-) / H b 9-G f p$ (NCAM 3wk; white bar), and $m$ Hb9-Gfp 16 mice injected with Endo-N (EndoN $3 w k$; black bar). ${ }^{*} p<0.05$ (compared with WT 3wk). 
number of collateral sprouts remaining in the cutaneous branch initially was quite puzzling. However, electrophysiological studies have shown that transected motor neurons remain viable for at least 2 years when they exclusively innervate skin (Nishimura et al., 1991). Thus it seems likely that misprojected collaterals withdraw only if they belong to motor neurons that also extend at least one collateral down an appropriate muscle pathway. The number of motor fibers in the distal pathways was the same as the number of fibers immediately distal to the lesion site in mice lacking PSA (Fig. 7C). This indicates that withdrawal of misprojecting motor axons is impeded if PSA is not present. The small number of double-labeled motor neurons in mice lacking PSA is presumably attributable to the fact that sprouting is restricted; thus the likelihood of collaterals reinnervating both muscle and cutaneous pathways is low (summarized in the supplemental material, available at www.jneurosci.org).

What impedes motor axons from withdrawing from inappropriate pathways when they lack PSA? At present it is not known. However, numerous cell adhesion molecules, such as laminins in the basal lamina and L1 in Schwann cells, are expressed in the distal nerve stump after peripheral nerve injury (Fu and Gordon, 1997). PSA is known to decrease these types of adhesive interactions (Tang et al., 1994; Fujimoto et al., 2001). Consequently, withdrawal of misprojected axons may be impeded in mice lacking PSA because the forward-directed growth, mediated by cell adhesion molecules, outweighs the signals to withdraw.

\section{PMR: permissive versus instructive guidance molecules}

When PSA is removed during development, nerves become more fasciculated (Landmesser et al., 1990; Tang et al., 1992; Rafuse and Landmesser, 2000), and many motor axons misproject to inappropriate muscles (Landmesser et al., 1990; Tang et al., 1992). Because PSA attenuates cell-cell interactions (Acheson et al., 1991; Rutishauser and Landmesser, 1996), these results indicate that PSA regulates axon targeting by allowing discrete groups of developing motor axons to respond to specific, instructive guidance molecules.

Based on developmental studies, it is logical to hypothesize that PSA also promotes PMR because it provides the necessary level of axon-axon de-adhesion that permits regenerating motor axons to respond to instructive guidance molecules expressed in the distal pathway and/or muscle fibers. The carbohydrate epitope HNK-1 is expressed preferentially by Schwann cells associated with the motor pathway (Martini et al., 1992); thus it could act as a short-range axon guidance molecule instructing regenerating motor axons to innervate the correct basal lamina tubes at the lesion site (Mears et al., 2003). However, several lines of evidence suggest that the distal targets are also important in regulating PMR. First, the number of motor neurons that correctly reinnervate the muscle pathway is reduced when all end organ (i.e., muscle and skin) contact is prevented (Brushart, 1993). Second, femoral motor neurons preferentially reinnervate cutaneous pathways under conditions in which skin contact is maintained, but muscle contact is prevented (Robinson and Madison, 2004). Although it is not known why this occurs, the authors suggest that motor neurons withdraw collaterals from distal targets containing low levels of trophic support while they simultaneously extend axons into pathways with relatively higher concentrations of trophic factors (Campenot, 1982). In this way the distal target providing the highest level of trophic support is reinnervated preferentially over time. When the end organs are present, as in the current study, the muscle provides more trophic support than does the cutaneous pathway, and, as a result, the motor pathway is reinnervated preferentially. However, when muscle reinnervation is prevented, the cutaneous pathway provides relatively more trophic support and thus becomes reinnervated preferentially (Robinson and Madison, 2004). Regardless of the instructive mechanisms underlying PMR, it is clear from the present study that regenerating motor neurons must express PSA to sprout supernumerary collaterals and mediate the withdrawal of inappropriate axons that project down cutaneous pathways. Thus, as occurs during development, instructive signals from distal targets cannot guide regenerating motor axons selectively unless PSA is present.

\section{References}

Abercrombie M (1946) Estimation of nuclear population from microtome sections. Anat Neurobiol Rec 94:239-247.

Acheson A, Sunshine JL, Rutishauser U (1991) NCAM polysialic acid can regulate both cell-cell and cell-substrate interactions. J Cell Biol 114:143-153.

Al-Majed AA, Neumann CM, Brushart TM, Gordon T (2000) Brief electrical stimulation promotes the speed and accuracy of motor axonal regeneration. J Neurosci 20:2602-2608.

Arber S, Han B, Mendelsohn M, Smith M, Jessell TM, Sockanathan S (1999) Requirement for the homeobox gene $\mathrm{Hb} 9$ in the consolidation of motor neuron identity. Neuron 23:659-674.

Boisseau S, Nedelec J, Poirier V, Rougon G, Simonneau M (1991) Analysis of high PSA N-CAM expression during mammalian spinal cord and peripheral nervous system development. Development 112:69-82.

Bonfanti L, Olive S, Poulain DA, Theodosis DT (1992) Mapping of the distribution of polysialylated neural cell adhesion molecule throughout the central nervous system of the adult rat: an immunohistochemical study. Neuroscience 49:419-436.

Brown DR, Everett AW (1990) Compartmental and topographical specificity of reinnervation of the gluteus muscle in the adult toad (Bufo marinus). J Comp Neurol 292:363-372.

Brown DR, Everett AW (1991) Position- and fibre type-dependent selectivity by regenerating motor axons in reformation of the topographical projection to the gluteus muscle in the adult toad (Bufo marinus). J Comp Neurol 309:495-506.

Brown DR, Everett AW, Bennett MR (1989) Compartmental and topographical distribution of axons in nerves to the amphibian (Bufo marinus) gluteus muscle. J Comp Neurol 284:231-241.

Brown MC, Booth CM (1983) Segregation of motor nerves on a segmental basis during synapse elimination in neonatal muscles. Brain Res 273:188-190.

Browne KM (1950) The spatial distribution of segmental nerves to striate musculature of the hindlimb of the rat. J Comp Neurol 93:441-445.

Brushart TM (1988) Preferential reinnervation of motor nerves by regenerating motor axons. J Neurosci 8:1026-1031.

Brushart TM (1993) Motor axons preferentially reinnervate motor pathways. J Neurosci 13:2730-2738.

Brushart TM, Seiler WA (1987) Selective reinnervation of distal motor stumps by peripheral motor axons. Exp Neurol 97:289-300.

Brushart TM, Witzel C (2003) The morphology of early peripheral axon regeneration. Soc Neurosci Abstr 29:152.10.

Brushart TM, Gerber J, Kessens P, Chen YG, Royall RM (1998) Contributions of pathway and neuron to preferential motor reinnervation. J Neurosci 18:8674-8681.

Brushart TM, Hoffman PN, Royall RM, Murinson BB, Witzel C, Gordon T (2002) Electrical stimulation promotes motoneuron regeneration without increasing its speed or conditioning the neuron. J Neurosci 22:6631-6638.

Campenot RB (1982) Development of sympathetic neurons in compartmentalized cultures. II. Local control of neurite survival by nerve growth factor. Dev Biol 93:13-21.

Chisholm A, Tessier-Lavigne M (1999) Conservation and divergence of axon guidance mechanisms. Curr Opin Neurobiol 9:603-615.

Covault J, Sanes JR (1985) Neural cell adhesion molecule (N-CAM) accumulates in denervated and paralyzed skeletal muscles. Proc Natl Acad Sci USA 82:4544-4548.

Covault J, Merlie JP, Goridis C, Sanes JR (1986) Molecular forms of N-CAM and its RNA in developing and denervated skeletal muscle. J Cell Biol 102:731-739. 
Cremer H, Lange R, Christoph A, Plomann M, Vopper G, Roes J, Brown R, Baldwin S, Kraemer P, Scheff S (1994) Inactivation of the N-CAM gene in mice results in size reduction of the olfactory bulb and deficits in spatial learning. Nature 367:455-459.

Delling M, Wischmeyer E, Dityatev A, Sytnyk V, Veh RW, Karschin A, Schachner M (2002) The neural cell adhesion molecule regulates cellsurface delivery of G-protein-activated inwardly rectifying potassium channels via lipid rafts. J Neurosci 22:7154-7164.

Dodd J, Morton SB, Karagogeos D, Yamamoto M, Jessell TM (1988) Spatial regulation of axonal glycoprotein expression on subsets of embryonic spinal neurons. Neuron 1:105-116.

El Maarouf A, Rutishauser U (2003) Removal of polysialic acid induces aberrant pathways, synaptic vesicle distribution, and terminal arborization of retinotectal axons. J Comp Neurol 460:203-211.

Franz C, Rafuse VF (2003) Involvement of PSA-NCAM in preferential motor reinnervation. Soc Neurosci Abstr 29:357.18.

Fu SY, Gordon T (1997) The cellular and molecular basis of peripheral nerve regeneration. Mol Neurobiol 14:67-116.

Fujimoto I, Bruses JL, Rutishauser U (2001) Regulation of cell adhesion by polysialic acid. Effects on cadherin, immunoglobulin cell adhesion molecule, and integrin function and independence from neural cell adhesion molecule binding or signaling activity. J Biol Chem 276:31745-31751.

Gorio A, Carmignoto G, Finesso M, Polato P, Nunzi MG (1983) Muscle reinnervation-II. Sprouting, synapse formation and repression. Neuroscience 8:403-416.

Guttmann E, Guttmann L, Medawar PB, Young JZ (1942) The rate of regeneration of nerve. J Exp Biol 19:14-44.

Kiss JZ, Wang C, Olive S, Rougon G, Lang J, Baetens D, Harry D, Pralong WF (1994) Activity-dependent mobilization of the adhesion molecule polysialic NCAM to the cell surface of neurons and endocrine cells. EMBO J 13:5284-5292.

Krarup C, Archibald SJ, Madison RD (2002) Factors that influence peripheral nerve regeneration: an electrophysiological study of the monkey median nerve. Ann Neurol 51:69-81.

Lance-Jones C, Landmesser L (1981) Pathway selection by chick lumbosacral motoneurons during normal development. Proc R Soc Lond B Biol Sci 214:1-18.

Landmesser L, Dahm L, Tang JC, Rutishauser U (1990) Polysialic acid as a regulator of intramuscular nerve branching during embryonic development. Neuron 4:655-667.

Laskowski MB, Sanes JR (1988) Topographically selective reinnervation of adult mammalian skeletal muscles. J Neurosci 8:3094-3099.

Mackinnon SE, Dellon AL, O’Brien JP (1991) Changes in nerve fiber numbers distal to a nerve repair in the rat sciatic nerve model. Muscle Nerve 14:1116-1122.

Madison RD, Archibald SJ, Brushart TM (1996) Reinnervation accuracy of the rat femoral nerve by motor and sensory neurons. J Neurosci 16:5698-5703.

Madison RD, Archibald SJ, Lacin R, Krarup C (1999) Factors contributing to preferential motor reinnervation in the primate peripheral nervous system. J Neurosci 19:11007-11016.

Martini R, Xin Y, Schmitz B, Schachner M (1992) The L2/HNK-1 carbohydrate epitope is involved in the preferential outgrowth of motor neurons on ventral roots and motor nerves. Eur J Neurosci 4:628-639.

McHanwell S, Biscoe TJ (1981) The localization of the motoneurons supplying the hindlimb muscles of the mouse. Philos Trans R Soc Lond B Biol Sci 293:477-508.

Mears S, Schachner M, Brushart TM (2003) Antibodies to myelinassociated glycoprotein accelerate preferential motor reinnervation. J Peripher Nerv Syst 8:91-99.

Milner LD, Rafuse VF, Landmesser LT (1998) Selective fasciculation and divergent pathfinding decisions of embryonic chick motor axons projecting to fast and slow muscle regions. J Neurosci 18:3297-3313.

Moscoso LM, Cremer H, Sanes JR (1998) Organization and reorganization of neuromuscular junctions in mice lacking neural cell adhesion molecule, tenascin-C, or fibroblast growth factor-5. J Neurosci 18:1465-1477.

Nemeth PA, Cope TC, Kushner S, Nemeth PM (1993) Spatial arrangement and metabolic capacity of fiber types in self-reinnervated cat muscle. Am J Physiol 264:C411-C418.

Nguyen QT, Sanes JR, Lichtman JW (2002) Pre-existing pathways promote precise projection patterns. Nat Neurosci 5:861-867.
Nishimura H, Johnson RD, Munson JB (1991) Rescue of motoneurons from the axotomized state by regeneration into a sensory nerve in cats. J Neurophysiol 66:1462-1470.

Olsen M, Zuber C, Roth J, Linnemann D, Bock E (1995) The ability to reexpress polysialylated NCAM in soleus muscle after denervation is reduced in aged rats compared to young adult rats. Int J Dev Neurosci 13:97-104.

Rafuse VF, Gordon T (1998) Incomplete rematching of nerve and muscle properties in motor units after extensive nerve injuries in cat hindlimb muscle. J Physiol (Lond) 509:909-926.

Rafuse VF, Landmesser LT (2000) The pattern of avian intramuscular nerve branching is determined by the innervating motoneuron and its level of polysialic acid. J Neurosci 20:1056-1065.

Rafuse VF, Polo-Parada L, Landmesser LT (2000) Structural and functional alterations of neuromuscular junctions in NCAM-deficient mice. J Neurosci 20:6529-6539.

Ramon y Cajal S (1928) Degeneration and regeneration of the nervous system. London: Oxford UP.

Ranson SW (1912) Degeneration and regeneration of nerve fibers. J Comp Neurol 22:487-545.

Rieger F, Nicolet M, Pincon-Raymond M, Murawsky M, Levi G, Edelman GM (1988) Distribution and role in regeneration of N-CAM in the basal laminae of muscle and Schwann cells. J Cell Biol 107:707-719.

Robinson GA, Madison RD (2003) Preferential motor reinnervation in the mouse: comparison of femoral nerve repair using a fibrin sealant or suture. Muscle Nerve 28:227-231.

Robinson GA, Madison RD (2004) Motor neurons can preferentially reinnervate cutaneous pathways. Exp Neurol 190:407-413.

Rutishauser U, Landmesser L (1996) Polysialic acid in the vertebrate nervous system: a promoter of plasticity in cell-cell interactions. Trends Neurosci 19:422-427.

Sanes JR, Marshall LM, McMahan UJ (1978) Reinnervation of muscle fiber basal lamina after removal of myofibers. Differentiation of regenerating axons at original synaptic sites. J Cell Biol 78:176-198.

Seddon JJ, Medawar PB, Smith H (1943) Rate of regeneration of peripheral nerves in man. J Physiol (Lond) 102:191-215.

Seki T, Arai Y (1993) Distribution and possible roles of the highly polysialylated neural cell adhesion molecule (NCAM-H) in the developing and adult central nervous system. Neurosci Res 17:265-290.

Shawe GDH (1955) On the number of branches formed by regenerating nerve-fibres. Br J Surg 42:474-488.

Soileau LC, Silberstein L, Blau HM, Thompson WJ (1987) Reinnervation of muscle fiber types in the newborn rat soleus. J Neurosci 7:4176-4194.

Sunderland S (1978) Nerves and nerve injuries. New York: Churchill Livingstone.

Tang J, Landmesser L, Rutishauser U (1992) Polysialic acid influences specific pathfinding by avian motoneurons. Neuron 8:1031-1044.

Tang J, Rutishauser U, Landmesser L (1994) Polysialic acid regulates growth cone behavior during sorting of motor axons in the plexus region. Neuron 13:405-414.

Tessier-Lavigne M, Goodman CS (1996) The molecular biology of axon guidance. Science 274:1123-1133.

Thaler J, Harrison K, Sharma K, Lettieri K, Kehrl J, Pfaff SL (1999) Active suppression of interneuron programs within developing motor neurons revealed by analysis of homeodomain factor HB9. Neuron 23:675-687.

Thompson W (1978) Reinnervation of partially denervated rat soleus muscle. Acta Physiol Scand 103:81-91.

Unguez GA, Bodine-Fowler SC, Roy RR, Pierotti DJ, Edgerton VR (1993) Evidence of incomplete neural control of motor unit properties in cat tibialis anterior after self-reinnervation. J Physiol (Lond) 472:103-125.

Wang L, Copray S, Brouwer N, Meek MF, Kernell D (2002) Regional distribution of slow-twitch muscle fibers after reinnervation in adult rat hindlimb muscles. Muscle Nerve 25:805-815.

Wichterle H, Lieberman I, Porter JA, Jessell TM (2002) Directed differentiation of embryonic stem cells into motor neurons. Cell 110:385-397.

Wilson S, Jesani M, Holder N (1988) Reformation of specific neuromuscular connections during axolotl limb regeneration: evidence that the first contacts are correct. Development 103:365-377.

Zhang Y, Campbell G, Anderson PN, Martini R, Schachner M, Lieberman AR (1995) Molecular basis of interactions between regenerating adult rat thalamic axons and Schwann cells in peripheral nerve grafts. I. Neural cell adhesion molecules. J Comp Neurol 361:193-209. 